\title{
Efficacy of Endodontic Irrigation Activation Systems on Enterococcus Faecalis Colonizing the Dentinal Tubules Using Confocal Laser Scanning Microscope: An In-Virto Study
}

\author{
Ameena Khaled Bagunaid ${ }^{1 *}$, Saied M Abdelazziz ${ }^{2}$, Somaia Abdulatif ${ }^{3}$ \\ and Fatma Abo Naeem ${ }^{4}$ \\ ${ }^{1}$ Master's Student, Faculty of Dentistry, Cairo University, Cairo, Egypt \\ ${ }^{2}$ Professor of Endodontics, Faculty of Dentistry, Cairo University, Cairo, Egypt \\ ${ }^{3}$ Professor of Microbiology, Faculty of Medicine, Cairo University, Cairo, Egypt \\ ${ }^{4}$ Lecturer of Endodontics, Faculty of Dentistry, Cairo University, Cairo, Egypt \\ *Corresponding Author: Ameena Khaled Bagunaid, Master's Student, Faculty of \\ Dentistry, Cairo University, Cairo, Egypt.
}

Received: February 08, 2021;

Published: March 06, 2021

(C) All rights are reserved by Ameena Khaled Bagunaid., et al.

\begin{abstract}
Aim: To assess the efficacy of two irrigation activation system with the Syringe needle irrigation on the percentage of viable Enterococcus faecalis colonizing the dentinal tubules of single-rooted teeth.

Methods: Fifty-one single-rooted human teeth were selected, instrumented using Fanta AF Blue S4 and Hyflex EDM up to size 40, autoclaved, and then inoculated with E. faecalis. The samples were randomly assigned into three main groups (n = 15), all were used to the method of irrigant activation. Group, I (EDDY tips), Group, II (XP-endo Finisher), Group, III (Syringe needle irrigation), and six teeth were used as a positive control. irrigation was done with $5.25 \%$ of $\mathrm{NaOCl}$ in all the samples. The teeth were split longitudinally with Isomet saw and examined with Confocal Laser Scanning Microscope (CLSM) to visualize the percentage of dead bacteria at different depths in the dentinal tubules at different canal locations.

Results: CLSM indicated that the experimental groups significantly reduced the overall bacterial percentage within the dentinal tubules when compared to the positive control. Besides EDDY tip showed better intratubular bacterial eradication efficacy than XPF and SNI in the coronal third, while both EDDY tip and XPF showed the same effect at the middle and apical thirds and both were higher than SNI.

Conclusion: None of the root canal irrigation methods resulted in complete bacterial eradication. Activation of $5.25 \% \mathrm{NaOCl}$ using either (EDDY tip or XPF) increased its intratubular bacterial eradication capacity.
\end{abstract}

Keywords: Endodontic Irrigation Activation; EDDY Sonic Tip; XP-Endo Finisher; Enterococcus Faecalis; Dentinal Tubules; CLSM

\section{Abbreviations}

SNI: Syringe Needle Irrigation; $\mathrm{NaOCl}$ : Sodium Hypochlorite; EDTA: Ethylenediaminetetraacetic Acid; E. faecalis: Enterococcus Faecalis; BHI: Brain Heart Infusion Broth; CFU: Colony Forming
Unites; CLSM: Confocal Laser Scanning Microscope; XPF: XP-Endo Finisher; SPSS: Statistical Package for Social Science. 


\section{Introduction}

Treatment of apical periodontitis is considered as one of the main goals of endodontic therapy. Efficient disinfection and intra-radicular bacterial reduction to at least under the critical level is mandatory for successful treatment. The most important reason for endodontic failure is the persistence of bacteria in the root canal and dentinal tubules after root canal treatment $[1,5]$. It was shown that large areas of the main root canal space are left untouched after mechanical instrumentation due to canal irregularities and dentinal tubules where the bacterial biofilm mainly colonize and persist even for years $[2,3]$.

Different types of bacterial species are included in endodontic infections. However, Enterococcus faecalis was repeatedly isolated from the failed treatment cases and mostly associated with persistent infection $[4,5]$. E. faecalis is a gram positive, facultative anaerobic bacterium which can survive in extreme conditions such as high alkaline $\mathrm{pH}$ resisting detergents and desiccation [6,7]. It is an aggressive bacteria with virulence factors enabling their adherence to the dentine, invasion of the dentinal tubules, and the ability to compete with the coexist bacterial species sharing their virulence traits $[4,8,9]$. For this reason, root canal debridement is an essential step to enhance the success rate of the treatment.

Sodium hypochlorite $(\mathrm{NaOCl})$ is the most widely used irrigating solution in endodontics. It is a broad-spectrum solution with proteolytic and dissolving properties on the organic tissues [5,11]. It can kill endodontic pathogens are organized in a biofilm and can be used with different concentrations ranging from 0.5 up to $5.25 \%$ $[10,12]$. It was found that the high surface tension of $\mathrm{NaOCl}$ solution can affect its ability to reach the complex canal irregularities and the difficult to reach areas in the root canal [12,13]. It has been shown that $\mathrm{NaOCl}$ can penetrate into the dentinal tubules up to 77-300 $\mu \mathrm{m}$ while E. faecalis can reach approximately $1000 \mu \mathrm{m}$ penetration depth $[5,17]$. In the conventional irrigation method, the irrigation solution is delivered into the canal using side vented needles where the irrigant only extends $1 \mathrm{~mm}$ beyond the needle tip. In addition, the vapor lock effect may develop within the canals by the action of $\mathrm{NaOCl}$ on the organic debris. This could interfere with the contact between the irrigant and the canal walls and prevent it from reaching beyond the entrapped air in the apical part of the canal $[14,15]$. These problems necessitate the development of disinfection protocols with specialized tools to improve the canal cleanliness, penetration of the irrigant toward the unreached areas and the dentinal tubule $[2,16]$.

One approach is using XPF (FKG Dentaire, Switzerland) in the final irrigation step to activate the irrigant solution maximizing its effect. XPF is a NiTi rotary finishing file with a small core size ISO 25 and zero taper. It is manufactured with MaxWire alloy with improved flexibility and ability to remove a significant amount of bacteria and debris from the main canal and a high percentage of bacterial reduction in the depth of dentinal tubules without compromising dentine $[17,18]$. Sonic activation of endodontic irrigation is another method used to improve the efficacy of canal disinfection. EDDY sonic tip (VDW, Munich, Germany) has been recently developed from a soft polyamide flexible material which powered at a high frequency up to $6,000 \mathrm{~Hz}$ by an air-scaler. It was claimed by the manufacturer that it can generate acoustic streaming and cavitations which enhance disinfection [19,20]. Many studies have investigated the passive sonic activation efficacy in canal cleanliness and the reduction of bacterial load in the canal lumen using scanning electron microscope and CFU [20,21]. More investigations are required to examine the intratubular bacterial reduction efficacy of the irrigation systems using a highly quantitative evaluation method as the novel CLSM. The aim of this study is to compare the efficacy of EDDY and XPF in the reduction of E. faecalis in the dentinal tubules using CLSM. The null hypothesis that there is no difference in the effect of both EDDY sonic tip and the XPF and Syringe needle irrigation on the percentage of viable E. Faecalis colonizing the dentinal tubules of single-rooted teeth.

\section{Materials and Methods}

Specimen preparation

Fifty-one extracted intact single-rooted human teeth were utilized in this study. The teeth were collected from the Department of Oral and Maxillofacial Surgery at Faculty of Dentistry, Cairo University. The teeth were scraped with a curette and cleaned, then inspected with the dental operative microscope and radiographed to confirm that all teeth are intact with a single canal excluding any tooth with internal canal defects and complexities, then stored in saline solution until use. The teeth were decoronated perpendicular to their long axis to a standardized length of $15 \mathrm{~mm}$ using a high-speed, water-cooled diamond disc. The canals were negotiated with a \#10 K-file (MANI, Tochigi, Japan) to establish apical patency and the working length was adjusted at $1 \mathrm{~mm}$ shorter of 
the apical foramen and then prepared using Fanta AF ${ }^{\mathrm{TM}}$ blue S4 Rotary files (Shanghai Fanta Dental Materials Co. Ltd, China) up to $\# 35 / .04$ and Hyflex EDM ${ }^{\mathrm{TM}}$ file (Coltene, Switzerland) \#40/.04 as final apical size. Canals were irrigated with $5.25 \% \mathrm{NaOCl}$ between instrumentation cycles using a disposable plastic syringe with 30G side-vented needles (Dia-Dent Group International, Korea) that positioned at $1 \mathrm{~mm}$ from the adjusted working length. The final rinse was performed with $2 \mathrm{ml}$ of normal saline followed by $3 \mathrm{ml}$ of $17 \%$ EDTA (Meta Biomed Co. Ltd, Korea) which was activated using an ultrasonic tip for two minutes, then flushed with $2.5 \% \mathrm{NaOCl}$. Then the canals were irrigated with $5 \mathrm{ml}$ of normal saline and dried with sterile paper points. A closed-end system was created sealing the root apices with composite material and painting a double layers of nail varnish over the root surface and left to dry for 24 hours. Then the teeth were autoclaved at $121^{\circ} \mathrm{C}$ for 30 minutes.

\section{Bacterial inoculation phase}

A suspension of E. faecalis American type ATCC 29212 was prepared in a Brain Heart Infusion broth (BHI) (Sigma-Aldrich, St. Louis, Missouri, USA) and maintained aerobically at $37^{\circ} \mathrm{C}$ for $24 \mathrm{~h}$. Then the bacterial culture was adjusted to McFarland standard No.1( $3 \times 108 \mathrm{CFU} / \mathrm{mL})$. First, each tooth root was placed in a microtube in which $800 \mu \mathrm{l}$ of sterile BHI broth was added and also injected into the canals, then the tubes were centrifuged (NÜVE, Ankara-Turkey) at $1500 \mathrm{~g}$ for 5 minutes to ensure the maximum penetration of the culture medium into the dentinal tubules. The BHI broth of the previous step was removed and $800 \mu$ l of the $E$. faecalis suspension was inserted with a micropipette into each root canal and the microtubes containing the roots. The microtubes were then centrifuged at a speed of $1500 \mathrm{~g}$ in two cycles, the first was for 5 minutes and the second was for 7 minutes. A fresh bacterial suspension was added between every centrifugation cycle where the solution already used was discarded. Then, a $100 \mu \mathrm{l}$ of E. faecalis suspension was added with 1-ml insulin syringes and a $30 \mathrm{G}$ needle, then incubated aerobically for $24 \mathrm{~h}$ at $37^{\circ} \mathrm{C}$ to facilitate bacterial recovery. On the second day all the roots in the microtubes were agitated in the vortex for 10 seconds and the fluid was discarded. Then $1 \mathrm{ml}$ of sterilized BHI broth was inserted into the microtubes, which again were agitated in the vortex for 10 seconds and incubated aerobically at $37^{\circ} \mathrm{C}$ for $24 \mathrm{~h}$. On the third and fourth day, the same steps were repeated as the first day and the second day, respectively. Finally, on the fifth day, the roots were removed from the microtubes.
Testing procedure

Teeth were divided randomly into three groups ( $\mathrm{n}=15$ teeth/ group) and 6 teeth as a positive control.

Group I: EDDY tip, Group II: XPF, Group III: SNI. All the canals were irrigated with a total of $10 \mathrm{ml}$ of $5.25 \% \mathrm{NaOCl}$ using a disposable plastic syringe with $30 \mathrm{G}$ side-vented needle for 2 minutes where the procedure was done by the same operator as follows:

Positive control; $(\mathrm{N}=6)$. No irrigation was performed.

EDDY; $(\mathrm{N}=15)$. $3 \mathrm{ml}$ of $5.25 \% \mathrm{NaOCl}$ was delivered into the canals for 30 seconds using 30G needle tip (Dia-Dent Group International, Korea) that positioned at $1 \mathrm{~mm}$ from the adjusted working length until the canal was filled. Then EDDY was inserted into the canals and positioned at $1 \mathrm{~mm}$ from the adjusted working length without binding and powered at $6000 \mathrm{~Hz}$ to activate the solution for 30 seconds. Another cycle of the previous two steps was repeated. Then a $4 \mathrm{ml}$ of $5.25 \% \mathrm{NaOCl}$ was injected into the canals without activation as a final flush for the irrigation. The tip was discarded after each use.

$\mathrm{XPF}$; $(\mathrm{N}=15) .3 \mathrm{ml}$ of $5.25 \% \mathrm{NaOCl}$ was delivered into the canals for 30 seconds using 30G needle tip that positioned at $1 \mathrm{~mm}$ from the adjusted working length until the canal was filled. XPF file was cooled down with an ethyl chloride spray while it was inside the tube. Then it was removed from the tube and placed in the contra-angle handpiece (E- Connect Pro Fast) and inserted in the canals and positioned at $1 \mathrm{~mm}$ from the adjusted working length and activated for 30 seconds at a speed of $1000 \mathrm{rpm}$ and a minimum torque of $0.5 \mathrm{~N} . \mathrm{cm}$ using a gentle $7-8 \mathrm{~mm}$ lengthwise movements. Another cycle of the previous two steps was repeated. Then the final flush was the same as EDDY group. The file was discarded after each use.

SNI; $(\mathrm{N}=15) .3 \mathrm{ml}$ of $5.25 \% \mathrm{NaOCl}$ was delivered into the canals for 30 seconds in up and down motion using 30G needle tip that positioned at $1 \mathrm{~mm}$ from the adjusted working length until the canal was filled followed by another 30 seconds without irrigation activation. Another cycle of the previous two steps was repeated. Then the final flush was the same as EDDY group. The needle tip was discarded after each use. 


\section{Confocal laser scanning microscope (CLSM)}

All the disinfected teeth samples were attached to acrylic blocks and sectioned longitudinally into two halves using IsoMet ${ }^{\mathrm{TM}}$ precision sectioning saw (Buehler Ltd., Lake Bluff, IL, USA). CLSM (Carl Zeiss, Göttingen, Germany) was used to examine the killing efficacy of the irrigation activation protocols on the viable bacteria within the dentinal tubules at different depths from the canal surface. Live/Dead bacterial viability stain was used consisting of acridine orang and propidium iodide. Both are nucleic acid stains used to stain the samples for 15 minutes according to the manufacturer's instructions. CLSM then was set at an excitation wavelength of 458nm for acridine orange (the green fluorescence representing living cells) and 514nm for propidium iodide (the red fluorescence representing the dead cells). The samples were inspected with X20 lens zoom. Sequential dual-channel imaging was used to display the green and red fluorescence to detect the viability and the distribution of the bacteria at depths $(50,100,150$, and $300 \mu \mathrm{m})$ at three canal locations (coronal, middle, and apical thirds). Then the images were acquired using Zen software at a resolution of $1024 \times 1024$ pixels.

\section{CLSM analysis}

First, the border of the internal root canal surface was located with the microscope and 3 randomly selected locations were scanned within the $5 \mathrm{~mm}$ of each third [24]. The quantification of the CLSM images for bacterial viability was done at 50, 100,150, and $300 \mu \mathrm{m}$ depths inside the dentinal tubules from the internal canal surface for the coronal, middle, and apical thirds using Zen software.

\section{Data analysis}

Average readings of the red and green intensities were taken for each depth at each third and dragged in the equation below to gain the percentage of the dead bacterial cells.

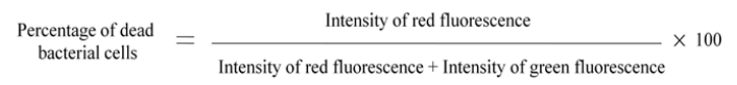

Three main variables of analysis were considered using the treatment groups (EDDY, XPF, and SNI), the canal locations (coronal, middle, and apical), and intratubular depths (50,100,150, and $300 \mu \mathrm{m})$. The percentage were analyzed using one-way ANOVA to identify the overall intratubular bacterial reduction of all groups and the positive control. The differences between the irrigation methods within the three canal locations were identified using the two-way ANOVA test. For more detailed identification of how the irrigation methods were effective in bacterial reduction at various depths of dentinal tubules within different canal locations, the extracted data from the dentinal tubular depth was stratified into four intratubular depths $(50,100,150$, and $300 \mu \mathrm{m})$ from the canal surface and then analyzed by the three-way ANOVA. The significance level was set at $\mathrm{P} \leq 0.05$. Statistical analysis was performed with IBM $^{\circledR 1}$ SPSS $^{\circledR 2}$ Statistics Version 20 for Windows.

\section{Results}

CLSM was used to evaluate the efficacy of the irrigation methods in driving the irrigant deeply inside the dentinal tubules for the reduction of the viable bacteria. The positive control confirmed the presence of the bacteria in the dentinal tubules. By comparing the positive control with the three experimental groups, all the groups (EDDY, XPF, and SNI) showed a much higher overall intratubular bacterial reduction than the positive control with a statically significant difference between them $(\mathrm{p}<0.001)$, table 1 .

\begin{tabular}{|l|l|c|}
\hline \multicolumn{1}{|c|}{ Methods of irrigation } & \multicolumn{2}{c|}{ Mean \pm Std. Dev } \\
\hline Group I (EDDY tip) & $45.37^{\mathrm{a}}$ & 3.85 \\
\hline Group II (XP-Finisher) & $44.25^{\mathrm{b}}$ & 4.41 \\
\hline Group III (SNI) & $41.66^{\mathrm{c}}$ & 2.96 \\
\hline Group IV (Positive control) & $28.75^{\mathrm{d}}$ & 5.63 \\
\hline p-value & \multicolumn{2}{|c|}{$<0.001^{*}$} \\
\hline
\end{tabular}

Table 1: Overall Mean and SD values of the dead bacterial cells in the tested groups.

*; significant ( $\mathrm{p}<0.05)$; ns; non-significant $(\mathrm{p}>0.05)$.

With respect to the canal locations (coronal, middle, and apical thirds) within $300 \mu \mathrm{m}$ depth of the dentinal tubules from the internal canal surface, the results demonstrated that EDDY tip showed

${ }^{1} \circledR$ IBM Corporation, NY, USA.

${ }^{2} \circledast$ SPSS, Inc., an IBM Company. 
a higher percentage of intratubular bacterial reduction in the coronal third followed by the middle third even the difference was not statistically significant $(p>0.05)$ followed by the apical third with a statistically significant difference was between the apical third and both the coronal and the middle thirds $(\mathrm{p}<0.05)$. In contrast, the XPF demonstrated a higher percentage of bacterial reduction efficacy in the middle third, followed by the coronal and then the apical third with a statistically significant difference between the middle and both the coronal and the apical thirds ( $p<0.05)$. The least percentage was found in the SNI group when compared with the EDDY and XPF groups where there was no statistically significant difference between the coronal, middle, and apical thirds ( $p$ > $0.05)$, figure 1.

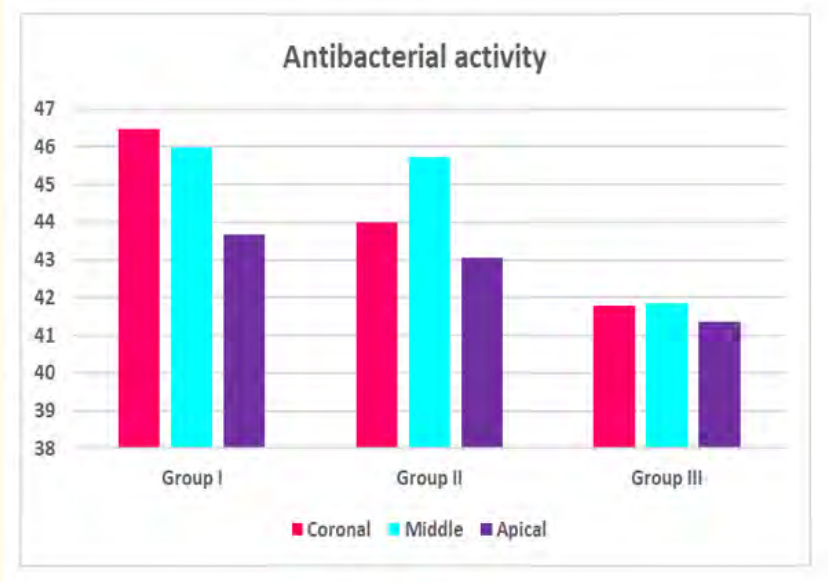

Figure 1: Bar chart representing the average percentage of dead cells at different canal locations.

For more detailed analysis of the effect of increasing the intratubular depth on the bacterial reduction efficacy of the irrigation methods as shown in (table 2 and figure 2), the intratubular depth of $300 \mu \mathrm{m}$ was stratified into four depths categories; 50, 100, 150, and $300 \mu \mathrm{m}$. In all the tested irrigation methods, the percentage of intratubular bacterial reduction was found to be reduced as the irrigant goes deeper in the dentinal tubules which was higher at $50 \mu \mathrm{m}$ followed by 100,150 , and $300 \mu \mathrm{m}$. For EDDY and XPF groups, the comparison between each pair of depths at the coronal, middle, and apical thirds showed a statistically significant difference $(\mathrm{p}<$ $0.05)$. For the SNI group, the comparison at the coronal, middle and apical thirds showed a statistically significant difference between each pair of depths $(\mathrm{p}<0.05)$, while the pairs of $(100 \mu \mathrm{m}$ vs $300 \mu \mathrm{m})$ and $(150 \mu \mathrm{m}$ vs $300 \mu \mathrm{m})$ in the apical third showed no statistically significant difference ( $\mathrm{p}>0.05)$.

Furthermore, It has been demonstrated that in the coronal third, the EDDY group was more efficient in the reduction of the intratubular bacteria within the depths of $50,100,150$, and $300 \mu \mathrm{m}$ than the XPF group even the difference was not statistically significant ( $p$ > 0.05). In the middle third, both of EDDY and XPF file showed an almost similar bacterial reduction efficacy at the tested depths $(50,100,150 \mu \mathrm{m})$ while at $300 \mu \mathrm{m}$, the EDDY had a slightly higher effect, but in all depths, the difference was not significant ( $p>0.05$ ). For the apical third, there was no significant difference between EDDY and XPF in which both showed an almost similar bacterial reduction percentage at $(150 \mu \mathrm{m}$ and $300 \mu \mathrm{m})$ and a slight increase in the effect with EDDY over XPF at $(50 \mu \mathrm{m}$ and $100 \mu \mathrm{m})$ but these results were not significant. In all the tested intratubular depths, the EDDY showed a higher effect than the SNI group at all the canal thirds with a statistically significant difference $(p<0.05)$, except in the apical third at $(150 \mu \mathrm{m}$ and $300 \mu \mathrm{m})$ the difference was not significant $(\mathrm{p}>0.05)$. The pair comparison between the XPF and the SNI showed that the XPF was more effective than the SNI at all the tested depths within the three canal thirds except at $300 \mu \mathrm{m}$ in the apical third they were almost similar. A non-significant difference was found within the coronal third and the apical third at $(100,150$, and $300 \mu \mathrm{m})$ with $(\mathrm{p}>0.05)$ while in the middle third and only at $50 \mu \mathrm{m}$ in the apical third, the difference was significant with $(\mathrm{p}<0.05)$.

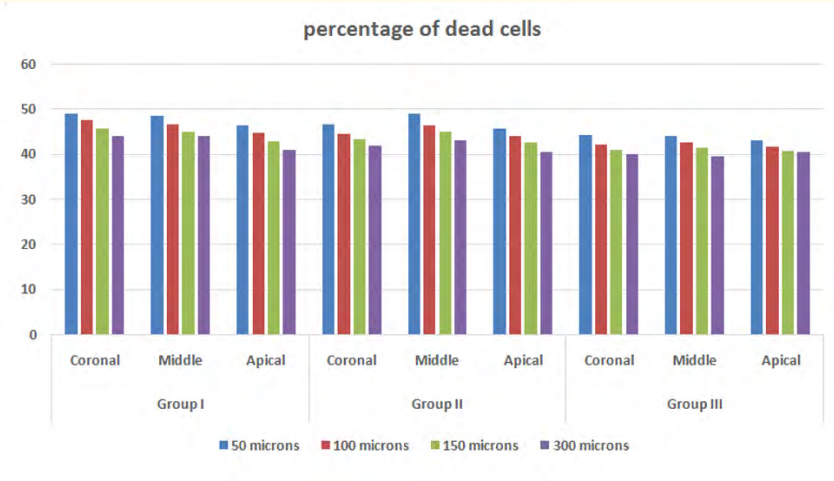

Figure 2: Bar chart representing the average percentage of dead cells (\%) for different groups at different depths from the surface at different canal locations. 
Efficacy of Endodontic Irrigation Activation Systems on Enterococcus Faecalis Colonizing the Dentinal Tubules Using Confocal Laser Scanning Microscope: An In-Virto Study

\begin{tabular}{|l|c|c|c|c|c|c|c|c|c|}
\hline \multirow{2}{*}{$\begin{array}{c}\text { Intra- tubular } \\
\text { depths }\end{array}$} & \multicolumn{3}{|c|}{$\begin{array}{c}\text { Group I } \\
\text { (EDDY tip) }\end{array}$} & \multicolumn{3}{c|}{$\begin{array}{c}\text { Group II } \\
\text { (XP EndoFinisher) }\end{array}$} & \multicolumn{3}{c|}{ Group III } \\
(SNI)
\end{tabular}

Table 2: The effect of the increase in depth on the intratubular bacterial reduction ability of different irrigation activation methods in each third of the root canal. *; significant $(\mathrm{p}<0.05)$; ns; non-significant.

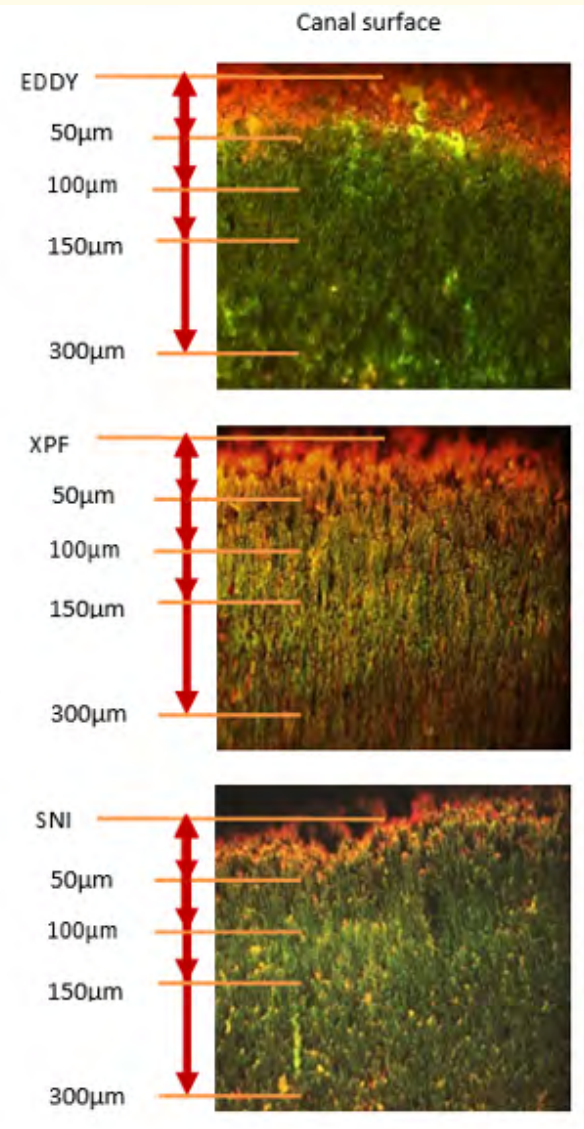

Coronal third
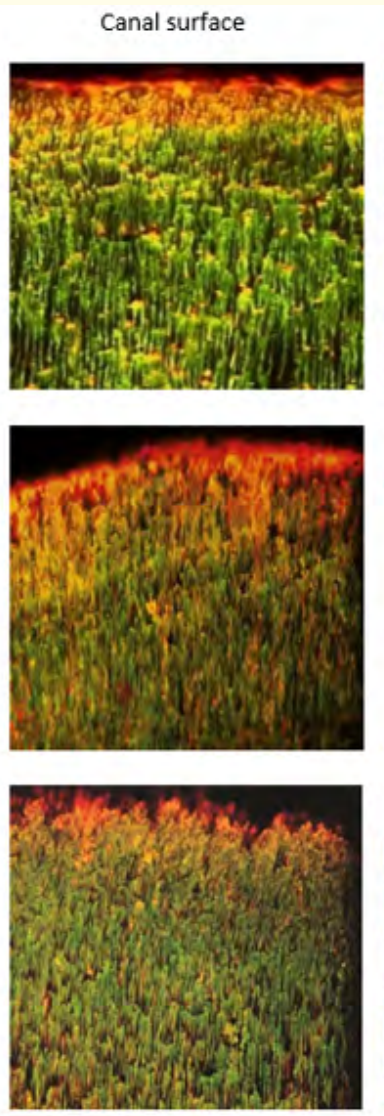

Middle third
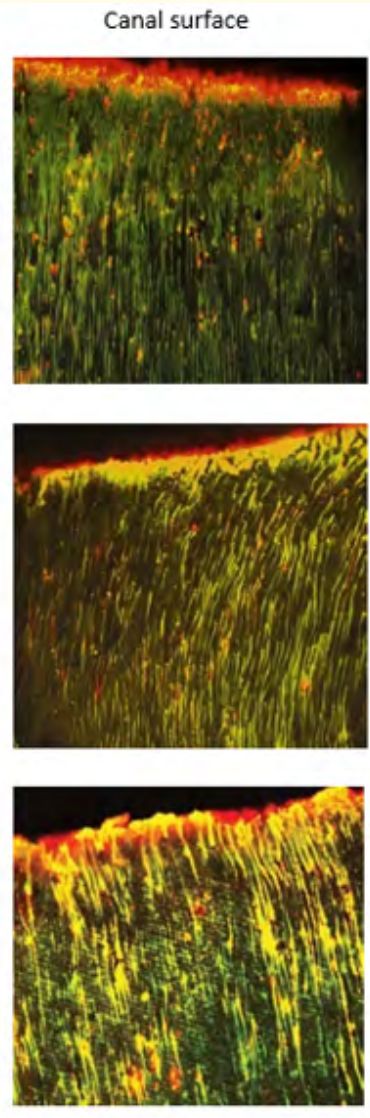

Apical third

Figure 3: CLSM images with 20x lens representing the

distribution of the intratubular bacteria, live bacteria (green fluorescence) and dead bacteria (red fluorescence) present in the coronal, middle and apical thirds within different depths in the dentinal tubules. 


\section{Discussion}

The present study aimed to evaluate the efficacy of the endodontic irrigant solution when activated using EDDY tip in comparison to XPF and the SNI on the reduction of E. faecalis at different depths in the infected dentinal tubules. The microbial colonies that resided in the root canals and colonizing the inaccessible areas due to anatomical complexities are able to multiply aggressively, invade the dentinal tubules utilizing the nutrients available due to leakage of obturation, unfilled lateral canals, or remaining un-removed dentin debris [5].

E. faecalis was chosen as it is highly resistant to antimicrobial agents which can tolerate a wide range of irrigants and medications. It can endure nutrients deprivation, enabling its survival in stressful environments. Furthermore, it has a round shape with a small cell diameter that can massively invade the dentinal tubules up to $1200 \mu \mathrm{m}$ depth and adhere to the demineralized dentine collagen where it is protected from the host's defense and the action of systematic antibiotics $[5,22,23]$.

In the contamination protocol, the samples were centrifuged to push the bacteria deep inside the tubules. First, the centrifugation was done with the BHI broth to ensure better penetration of the broth in the tubules providing the needed nutrients to the bacteria. A $24 \mathrm{~h}$ incubation period was established to give the bacteria a chance for recovery from any damage that could happen during the centrifugation $[24,25]$.

(NaOCl) 5.25\% was chosen due to its wide antibacterial efficacy which can inactivate bacterial proteins [5]. It was demonstrated that the antibacterial efficacy of $(\mathrm{NaOCl})$ and ability to penetrate the dentinal tubules can be enhanced by its concentration. When increasing the concentration from $1 \%$ to $6 \%$, the penetrability of $\mathrm{NaOCl}$ can be improved up to $50 \%$ inside the dentinal tubules $[9,26]$. 17\% EDTA was used before the contamination of the samples to remove the smear layer and smear plug and ensure that the dentinal tubules are patent for bacterial penetration [24]. A closed system was established to create a closed room in the canals and act as a reservoir for the irrigant during the activation process without leaking apically. besides, double layers of the nail varnish were painted on the root surface to ensures that the bacterial contamination occurred only through the main root canal $[24,25]$. The bacterial viability was evaluated using CLSM which allows for in-depth analysis of biological structure without causing damage, provides better visualization of the presence and distribution of bacteria in the dentinal tubules generating quantitative data for the tubules that are not open to the surface [24,27-29]. CLSM was chosen rather than the colony-forming unite because CFU only provides information about the existence of the bacteria and their estimated number rather than the exact cell counts as its sensitivity was considered insufficient for detecting possible viable bacteria in lower concentration $[5,30]$.

The present study compared three different irrigation activation methods in their penetration capabilities into the dentinal tubules to kill bacteria using the CLSM by calculating the percentage of live/dead bacteria in the infected dentinal tubules at the coronal, middle and apical thirds at different intratubular depths. The results found that none of the three experimental groups showed complete elimination of $E$. faecalis from the dentinal tubules and demonstrated a significantly higher overall percentage of bacterial reduction in the tubules when compared with the positive control which was in accordance with previous studies [5,31].

The tested irrigation methods showed a higher intratubular bacterial reduction in the coronal and middle thirds when compared with the apical third. This might be attributed to the more peritubular and sclerosed dentin in the apical third with a decreased number of dentinal tubules, and the more available space in the coronal and middle thirds due to the increased canal taper providing enough room for the irrigant to be activated and circulated within the canal $[17,32]$. This was in accordance with a study that demonstrated a significantly higher bacterial reduction efficacy in the dentinal tubules at both coronal and middle thirds than the apical third using EDDY tip to activate 3\% $\mathrm{NaOCl}$ [5]. Another study demonstrated that the canal cleanliness and smear layer removal in the apical portion of the root canal were minor compared with the middle and coronal portions as the canal diameter in the apical third can impact the effectiveness of debris removal and the exchange of irrigant [21]. In addition, XPF showed a higher bacterial reduction efficacy in the middle third over the coronal and then the apical thirds which was in disagreement with Azim., et al. (2016) [17] who showed that the efficacy of XPF was higher in the coronal third followed by the middle third.

It has been found that both EDDY tip and XPF showed higher overall intratubular bacterial reduction than the SNI at the coronal,

Citation: Ameena Khaled Bagunaid., et al. "Efficacy of Endodontic Irrigation Activation Systems on Enterococcus Faecalis Colonizing the Dentinal Tubules Using Confocal Laser Scanning Microscope: An In-Virto Study". Acta Scientific Dental Sciences 5.4 (2021): 04-13. 
middle and apical thirds. This can be attributed to the biomechanical effect of both activation systems that might have driven the $\mathrm{NaOCl}$ deeply in the dentinal tubules to kill the resided bacteria. For the EDDY tip, the acoustic streaming and cavitations effects and the high amplitude of the tip movement created by the sonic energy can influence the hydrodynamic phenomenon increasing the shear stress on the canal walls and help in debris removal and enhance the flow of the irrigant into the inaccessible areas within the root canal $[5,33,21]$. For the XPF, its mechanical effect with its special design and the highly flexible proprietary alloy can promote the agitation of the irrigant inside the canal enabling the dislodgement and removal of debris [34]. Upon stratification of the dentinal tubular depth, both EDDY and XPF showed no significant difference with the SNI at (150 and $300 \mu \mathrm{m})$ in the apical third which indicated that the efficacy of the irrigation methods decreases by increasing the depth of the dentinal tubule where the colonized bacteria resided and even can multiply in favorable conditions. These results were in agreement with Zeng., et al. (2018) [5] who demonstrated the significant antibacterial efficiency of EDDY tip over SNI using $3 \%$ of $\mathrm{NaOCl}$ in the first $100 \mu \mathrm{m}$ from the intracanal surface. However, this efficacy was reduced beyond $100 \mu \mathrm{m}$ where no significant difference was discerned between them. This might be attributed to the reduced concentration of $\mathrm{NaOCl}(3 \%)$ as the antibacterial efficacy of $\mathrm{NaOCl}$ was shown to be increased by increasing its concentration [31]. Another study demonstrated that EDDY tip was able to increase the antibacterial efficacy of the irrigating solution which improved the removal of smear layer and debris from the root canal wall and enhance the penetration capacity of the irrigating solution deeper into the dentinal tubules [35]. Furthermore, many studies demonstrated a significant increase in the antibacterial efficacy of the irrigating solution $\mathrm{NaOCl}$ and its effect on canal cleanliness of debris and smear layer removal when used in conjunction with EDDY tip [21,36,37]. Also, the observation of the XPF efficacy was in agreement with Azim., et al. (2016) [17] where it had the highest level of dead bacteria over the SNI at $50 \mu \mathrm{m}$ in the dentinal tubules. Also, our results showed that both EDDY and XPF showed an almost similar intratubular bacterial reduction efficacy with no significant difference. Another study demonstrated a significant higher capacity of XPF file in debris and smear layer removal over EDDY tips [36]. The differences in the results between the studies may stem from the differences in the methodology, the type of the samples, and its preparation protocol in addition to the volume of irrigation and its concentration.

\section{Conclusion}

Within the limitation of the study, it may be concluded that activation of $5.25 \% \mathrm{NaOCl}$ with EDDY tip and XPF increased the intratubular bacterial reduction capacity of the irrigant as well as its penetration capability inside the dentinal tubules. In addition, Both were more effective in bacterial eradication than the traditional SNI method even though none of the root canal irrigation activation methods can result in complete bacterial eradication especially which resided deeply within the dentinal tubules of the root canals.

\section{Conflict of Interest}

There is no conflict of interest in the study.

\section{Bibliography}

1. Siqueira JF and Rôças IN. "Clinical Implications and Microbiology of Bacterial Persistence after Treatment Procedures". Journal of Endodontics 34.11 (2008): 1291-1301.

2. Vieira AR., et al. "Dentinal Tubule Infection as the Cause of Recurrent Disease and Late Endodontic Treatment Failure : A Case Report". Journal of Endodontics 38.2 ( 2012): 250-254.

3. Zehnder M and Belibasakis GN. "On the dynamics of root canal infections-what we understand and what we don't". Virulence 6.3 (2015): 216-222.

4. Zeng C., et al. "Antibacterial efficacy of an endodontic sonic-powered irrigation system : An in vitro study". Journal of Dentistry 75 (2018): 105-112.

5. Zhang C., et al. "Correlation between Enterococcus faecalis and Persistent Intraradicular Infection Compared with Primary Intraradicular Infection : A Systematic Review". Journal of Endodontics 41.8 (2015): 1207-1213.

6. Tendolkar PM., et al. "Pathogenic enterococci: new dev elopments in the 21 st century". Cellular and Molecular Life Sciences 60.12 (2003): 2622-2636.

7. Rôças IN. "Association of Enterococcus faecalis With Different Forms of Periradicular Diseases". Journal of Endodontics 30.5 (2004): 315-320.

8. Love RM. "Enterococcus faecalis - a mechanism for its role in endodontic failure". International Endodontic Journal 34.5 (2001): 399-405. 
9. Hubble TS., et al. "Influence of Enterococcus faecalis proteases and the collagen-binding protein, Ace, on adhesion to dentin". Oral Microbiology and Immunology 18.2 (2003): 121-126.

10. Frough-reyhani M., et al. "Antimicrobial efficacy of different concentration of sodium hypochlorite on the biofilm of Enterococcus faecalis at different stages of development". Journal of Clinical and Experimental Dentistry 8.5 (2016): e480-e484.

11. Zehnder M., et al. "Tissue-dissolving capacity and antibacterial effect of buffered and unbuffered hypochlorite solutions". Oral Surgery, Oral Medicine, Oral Pathology, Oral Radiology, and Endodontics 94.6 (2002): 756-762.

12. Giardino L., et al. "Comparative wettability of different sodium hypochlorite solutions". Giornale Italiano di Endodonzia 26.2 (2012): 57-62.

13. Giardino L., et al. "Surface Tension Comparison of Four Common Root Canal Irrigants and Two New Irrigants Containing Antibiotic". Journal of Endodontics 32.11 (2006): 1091-1093.

14. Tay FR., et al. "Effect of Vapor Lock on Root Canal Debridement by Using a Side-vented Needle for Positive- pressure Irrigant Delivery". Journal of Endodontics 36 (2010): 745-750.

15. Zand V., et al. "Antibacterial efficacy of different concentrations of sodium hypochlorite gel and solution on Enterococcus faecalis biofilm". Iranian Endodontic Journal 11.4 (2016): 315-319.

16. Zou L., et al. "Penetration of Sodium Hypochlorite into Dentin". Journal of Endodontics 36.5 (2010): 793-796.

17. Azim AA., et al. "Efficacy of 4 Irrigation Protocols in Killing Bacteria Colonized in Dentinal Tubules Examined by a Novel Confocal Laser Scanning Microscope Analysis". Journal of Endodontics 42.6 (2016): 928-934.

18. Bao P., et al. "In Vitro Efficacy of XP-endo Finisher with 2 Different Protocols on Biofilm Removal from Apical Root Canals". Journal of Endodontics 43.2 (2017): 321-325.

19. VDW manufacturer brochure EDDY®. Munich. 19.10.2017.

20. Neuhaus KW., et al. "Antibacterial Efficacy of a New Sonic Irrigation Device for Root Canal Disinfection". Journal of Endodontics 42.12 (2016): 1799-1803.
21. Urban K., et al. "Canal cleanliness using different irrigation activation systems: a SEM evaluation". Clinical Oral Investigation 21.9 (2017): 2681-2687.

22. Vatkar NA., et al. "Vitality of Enterococcus faecalis inside dentinal tubules after five root canal disinfection methods". Journal of Conservative Dentistry 19.5 (2016): 445-449.

23. Dos Santos Antonio MP., et al. "Bactericidal effects of two parameters of Er: YAG laser intracanal irradiation : ex - vivo study". Lasers in Medical Science 27.6 (2012): 1165-1168.

24. Ma J., et al. "A new noninvasive model to study the effectiveness of dentin disinfection by using confocal laser scanning microscopy". Journal of Endodontics 37.10 (2011): 1380-1385.

25. Andrade FB., et al. "A new improved protocol for in vitro intratubular dentinal bacterial contamination for antimicrobial endodontic tests : standardization and validation by confocal laser scanning microscopy". Journal of Applied Oral Science 23.6 (2015): 591-598.

26. Vandrangi P. “Evaluating Penetration Depth of Treatment Fluids into Dentinal Tubules Using the GentleWave $®$ System". Dentistry 6.3 (2016): 3-7.

27. Cerca N., et al. "Confocal laser scanning microscopy analysis of S. epidermidis biofilms exposed to farnesol, vancomycin and rifampicin". BMC Research Notes 16.5 (2012): 244.

28. St Croix CMS., et al. "Confocal microscopy: comparisons, applications, and problems". Biotechniques 39.6 (2005): 2-5.

29. Nair VS., et al. "Detection of adherence of Enterococcus faecalis in infected dentin of extracted human teeth using confocal laser scanning microscope: An In vitro Study". Journal of Pharmacy and Bioallied Sciences 1 (2017): 41- 44.

30. Mathew J., et al. "Viability and antibacterial efficacy of four root canal disinfection techniques evaluated using confocal laser scanning microscopy". Journal of Conservative Dentistry 17.5 (2014): 444-448.

31. Wong DTS and Cheung GSP. "Extension of Bactericidal Effect of Sodium Hypochlorite into Dentinal Tubules". Journal of Endodontics 40.6 (2013): 825-829. 
32. Brunson M., et al. "Effect of apical preparation size and preparation taper on irrigant volume delivered by using negative pressure irrigation system". Journal of Endodontics 36.4 (2010): 721-724.

33. Ruddle CJ. "Endodontic disinfection : Tsunami irrigation". Saudi Endodontic Journal 5.1 (2015): 1-12.

34. Leoni GB., et al. "Ex vivo evaluation of four final irrigation protocols on the removal of hard-tissue debris from the mesial root canal system of mandibular first molars". International Endodontic Journal 50.4 (2017): 398-406.

35. Mancini M., et al. "Smear Layer Removal and Canal Cleanliness Using Different Irrigation Systems (EndoActivator, EndoVac, and Passive Ultrasonic Irrigation): Field Emission Scanning Electron Microscopic Evaluation in an In Vitro Study". Journal of Endodontics 39.11 (2013): 1456-1460.

36. Tipanta S., et al. "Efficacy of smear layer removal from root canals using three agitation devices". Endodontic Practice Us 12.2 (2019): 25-28.

37. Plotino G., et al. "Efficacy of sonic and ultrasonic irrigation devices in the removal of debris from canal irregularities in artificial root canals". Journal of Applied Oral Science 7.27 (2019): e20180045.

\section{Assets from publication with us}

- Prompt Acknowledgement after receiving the article

- Thorough Double blinded peer review

- Rapid Publication

- Issue of Publication Certificate

- High visibility of your Published work

Website: www.actascientific.com/

Submit Article: www.actascientific.com/submission.php

Email us: editor@actascientific.com

Contact us: +919182824667

Citation: Ameena Khaled Bagunaid., et al. "Efficacy of Endodontic Irrigation Activation Systems on Enterococcus Faecalis Colonizing the Dentinal Tubules Using Confocal Laser Scanning Microscope: An In-Virto Study". Acta Scientific Dental Sciences 5.4 (2021): 04-13. 